\title{
Message Strategies and Media Formats of Florists' Facebook Posts and Their Effects on Users' Engagement Behaviors
}

\author{
Li-Chun Huang ${ }^{1}$ and Li-Chun Chen \\ Department of Bio-Industry Communication and Development, National \\ Taiwan University, Taipei 10617, Taiwan
}

Additional index words. flowers, floral market, consumer, social media, ANOVA

\begin{abstract}
Social media marketing has been widely adopted by florists with the use of the Facebook brand page. However, many florists fail to achieve their expected success in that realm because of not being fully conversant in posting on social media. To address this deficiency, this study aims to 1) develop a taxonomy of florists' Facebook posts to clarify florists' message strategies on Facebook brand page and 2) investigate the effect of posted messages and media formats on the marketing performance of florists' Facebook brand pages by evaluating users' engagement based on the number of likes, comments, and shares from users for each post. Using data derived from 1646 empirical Facebook posts initiated by florists, it was found that florists' Facebook posts could be classified into four broad message types covering 12 categories. The statistical results for analysis of variance (ANOVA) and post hoc tests revealed that the posted message and media format had significant effects in terms of causing users to like, comment on, or share florists' posts. Compared with other message categories, posts in the message categories of product information, gratitude to customers, and holiday greetings had more favorable effects in terms of causing users to like, comment on, or share florists' posts. As for the effect of media format, it was the posts in the photo media format that attracted more likes, comments, and shares from users compared with those in other media formats. Florists who operate brand pages on Facebook can be guided by our research when making decisions regarding the post characteristics in message orientations and media formats for attracting favorable responses from users.
\end{abstract}

Most of the florists are small enterprises that have little in terms of a budget for marketing through conventional media. Therefore, finding a substitute medium that is more economical and applicable to consumers' communication behavior in the modern Internet era has become crucial for these businesses. Characterized by a large user population, low cost, and ease of use, social media have become that substitute and have been increasingly adopted by florists for marketing their products. Numerous social media networks exist (Kaplan and Haenlein, 2010), but Facebook is the most popular social media network worldwide (Nelson, 2010; Stankov et al., 2010; Wilson et al., 2012).

It has been reported that between $39 \%$ and $61 \%$ of florists in the United States have adopted social media in marketing, with

Received for publication 22 June 2018. Accepted for publication 11 Sept. 2018.

This research was funded by the Ministry of Science and Technology of Taiwan under Grant MOST 106-2410-H-002-203.

The authors would like to thank the anonymous reviewers for their thoughtful comments and suggestions.

${ }^{1}$ Corresponding author. E-mail: lihuang@ntu.edu. tw. younger flower shop managers or those working in large flower shops exhibiting a higher adoption rate (Prince and Prince, 2014). Because of their benefits in marketing, scholars have urged florists to integrate social media into the marketing communication work (Hall et al., 2012). In the case of 1800-Flowers.com, consumers cannot only make purchases on the official Facebook brand page, but they can also gain valuable information for reference from the official Facebook brand page for making the most satisfactory purchasing decisions (Anderson et al., 2011; Baird and Parasnis, 2011; Kaplan and Haenlein, 2010).

As florists are gradually treating social media as a comprehensive integrated marketing communication tool, the return on investment in social media marketing must be determined to assist florists in developing marketing strategies. The method for evaluating marketing performance on social media differs from that for conventional media. Conventional media advertising seeks increased brand awareness, positive attitudes, and memorability after broadcast, which are expected to increase sales volume. As a result, conventional media marketing often uses financial indicators as the basis for evaluating marketing performance (Weinberg and Pehlivan, 2011). Unlike conventional media, social media are characterized by high social interactivity, the application of which focuses on triggering consumers' actual behavioral participation to converse, share, and cocreate with other consumer members for achieving the goal of brand awareness, brand loyalty, and word of mouth, which will have a more durable, positive effect on sales (Hoffman and Fodor, 2010). If financial performance is used as the measure for social media marketing performance, then the characteristic of social interactivity is overlooked.

Therefore, scholars have commonly suggested using users' engagement behaviors of liking, commenting on, or sharing posts as marketing performance indicators of an enterprise's Facebook brand page (Cvijikj and Michahelles, 2013; Sabate et al., 2014; Tafesse, 2015). Consumers' response behaviors of liking, commenting on, and sharing posts have a double meaning for marketing: 1) they reflect the degree of consumer engagement with the brand and 2) they increase the exposure of an enterprise's brand messages. It is the so-called the like economy of social media (Gerlitz and Helmond, 2013). As a message disseminated by an enterprise on social media triggers users to discuss, provide feedback, or actively share the information with others, the enterprise's act is considered effective social media management (Hoffman and Fodor, 2010; Weinberg and Pehlivan, 2011). This reflects the importance of Facebook brand page management to enterprises, in particular the composition of contents posted.

Previous studies for other industries besides floriculture have highlighted the importance of the message contained in a post and its media format in terms of triggering the abovementioned social media response behaviors. However, consumers in various industries seem to have distinct preferences regarding the message and media format of a post. For example, scholars focusing on the Facebook posts in the food, beverage, and automobile industries have discovered that the numbers of likes that entertaining posts receive have far outnumbered those of posts in other content categories (Cvijikj and Michahelles, 2013; Tafesse, 2015). By contrast, De Vries et al. (2012) analyzed posts from the Facebook brand pages of various industries and discovered that entertaining posts received fewer likes than posts in other categories. As for promotional posts, Luarn et al. (2015) examined posts from the Facebook brand pages of companies in multiple industries, and revealed that promotional posts with messages regarding purchase discounts, samples or coupons received the most likes from users. However, Tafesse (2015) found that promotional posts did not have significant effects in terms of triggering users to like or share the Facebook posts in the automobile industry.

The media format employed in a post is also a critical factor affecting users' response behaviors on Facebook because of its effect on the perceived information richness of a post, which influences the effectiveness of the post in communicating to consumers 
(Daft and Lengel, 1986; Lengel and Daft, 1988). Therefore, a suitable media format can increase the clarity of message communication. The media formats frequently employed in Facebook posts include text, photos, videos, and links (Cvijikj and Michahelles, 2013; Kwok and Yu, 2013; Su et al., 2015). Similarly, although the media format has generally proved to be effective in increasing users' responses to Facebook posts, study results differ with media format being the most effective. For example, Kim et al. (2015) investigated posts initiated by various industries and discovered that posts with photos were more effective in eliciting responses from users than posts with only text or videos, but the effect differed from industry to industry. Luarn et al. (2015), however, obtained different findings as they looked at the Facebook posts of various industries and found that posts with links and videos were more effective in triggering likes, comments, and shares by users.

Because of the importance of social media in the marketing communication and future prospects of the floral industry, the amount of related research has increased in recent years. For example, Hall et al. (2012) analyzed the importance of social media to florists and provided suggestions on how to operate social media successfully in the floral market. Prince and Prince (2014) surveyed the social media adoption rate for florists and investigated whether the adoption of social media was salient to the success of the florists' business. In addition, Yue et al. (2016) explored the activities and contents of posts that millennial consumers preferred for florists on social media platforms. Several studies on consumer floral purchasing behaviors have highlighted the importance of social media in the floral market. For example, an investigation by Russell Research (2016) revealed that social media were the third major source of information on floral products for the $\mathrm{X}$ and $\mathrm{Y}$ generations, being surpassed only by family/friends and TV. In particular, Facebook is the social networking platform most widely adopted by the consumers of the younger generations (Irani et al., 2011; Yue et al., 2016).

Although Facebook has become the main social networking platform for consumers to gain information on floral products, how consumers respond toward different types of florists' Facebook posts has not been explored. To address this deficiency, this study aims to 1) develop a taxonomy of florists' Facebook posts to clarify florists' current message strategies on Facebook brand pages and 2) examine the effect of posted messages and media formats in terms of triggering consumers' responses of liking, commenting on, and sharing these Facebook posts.

The goals of this study were implemented using data obtained from empirical Facebook posts initiated by florists in Taiwan. About $80 \%$ of the florists in Taiwan are located in metropolitan areas. In particular, $70 \%$ of them are in the Taipei capital area, with many of them feeling the burden of the increasing rent for store space on their business operations. Subsequently, many florists have closed their physical stores or relocated to more remote alleys, with the result that online flower shops have become an alternative plan for these florists to continue to run their businesses (Yuan, 2010). Because of this industrial background and the high reach of Facebook among the Taiwanese population in that $75 \%$ of Taiwan residents have a Facebook account (Taipei Times, 2014), many florists have created a business page on Facebook as part of an attempt to increase the exposure of their brands. Therefore, this study provides empirical evidence that is valid in examining the study questions targeted in this study. The study's results can serve as a reference for florists who are interested in improving their performance in social media marketing.

\section{Materials and Methods}

Data collection. To obtain empirical data for this study, the researchers searched for florists' brand pages on Facebook with the keyword "flower shop" in Chinese and found 100 Facebook brand pages. Next, the following criteria were adopted to filter the search results to select the brand pages that satisfied the research requirements: 1) the page owner is a local florist in Taiwan, 2) the products are mainly fresh flowers, and 3) the Facebook page is currently in operation. The filtering results revealed that among the 100 pages, 62 were not established by local Taiwanese florists, 12 belonged to florists whose main operations were not fresh flowers but venue decoration only or dry flowers, and two had not posted anything in the previous year. Excluding the aforementioned pages yielded 24 Facebook brand pages for subsequent data collection.

We applied the software Power Query to download data from the selected florists' brand pages. Power Query, a free software released by Microsoft Company, is a data query tool used to retrieve data from outer sources for academic or commercial studies. The web contents captured by Power Query can be reproduced in Excel, allowing the researchers to edit, convert, calculate, or transmit the data (Microsoft, 2018; Webb, 2014). In the application of Power Query, we first entered florists' Facebook IDs as the identification of the data source and then the content of the posts from selected florists was downloaded with the functionality of Power Query. When retrieving posts, this study set the date for the beginning of data collection, 1 May 2016, as the benchmark, retrieving florists' posts from the year before that day. All posts in that year were regarded as the data to be analyzed in this study. As the posts were retrieved successfully and displayed in Excel worksheets automatically, we used the Query Editor to write formulas for Power Query to retrieve the number of likes, comments, and shares gained from users for each post.
In total, 1646 posts were downloaded from the selected brand pages. The text of each post was recorded verbatim. The totals for likes, comments, and shares that each post received from users were recorded directly. In addition, the media format of a post was recorded according to four categories, namely, "text (text only)," "photo (inserting a photo)," "video (embedding a video)," and "link (containing a URL)."

Developing a taxonomy of florists' Facebook posts. This study sought to develop a taxonomy of florists' post contents, to clarify florists' message strategies on the Facebook brand page. A content analysis was performed on the 1646 posts to achieve the goal of this study (DowneWamboldt,1992). The first step was to construct a categorization frame for subsequent post classification. Using the template analysis approach (Crabtree and Miller, 1992), post categories that had been published in the literature by researchers, such as Cvijikj and Michahelles (2013), Coursaris et al. (2013), Leung et al. (2017), Luarn et al. (2015), Su et al. (2015), and Tafesse (2015), were considered when creating and defining categories for the classification of posts in this study. Next, the text for each of the 1646 posts was analyzed. Based on the themes of the text, the posts were classified into the established categories (Kassarjian, 1977). If the content of a post could not be classified into an established category, then open coding was adopted along with text analyzing to establish a new category under the existing classification framework, and we organized the post into that new category to ensure that none of the content was restricted by the proposed classification framework (Corbin and Strauss, 1990).

Interjudge reliability was adopted to ensure the reliability of the classification results. First, a person experienced in the methodology of content analysis was invited to be a cocoder to participate in coding and classifying the posts. The second author explained the coding logic and the established categorization framework to the cocoder, and then the second author and the cocoder independently completed the coding and categorization work on the 1646 posts. Next, the classification results were compared. A total of 1546 posts were classified into the same categories, whereas the other 100 posts were classified differently. According to the calculation formula of interjudge reliability, namely, the ratio of coding agreements to the total number of coding decisions $(r / R)$, the agreeability of the classification results was $93.92 \%$, exceeding the suggested threshold of $85 \%$; thus, the categorization results possessed reliability (Kassarjian, 1977). As for the 100 posts classified differently, a second cocoder experienced in content analysis was invited to participate in the classification task. The procedure of content analysis was repeated as many times as needed until the second author and the two cocoders all agreed on the classification results. 
Analyzing the effect of posted messages and media formats in terms of triggering users' engagement behaviors. In this section, the numbers of likes, comments, and shares that each post received were recorded as the measures of users' engagement behaviors in relation to florists' posts. The number of likes that a post received was recorded according to how many users clicked the "like" button for that post, using user accounts as identification. The number of comments was recorded with the total number of comments that a post received. A single user could leave one or more comments on the post. The number of shares was recorded based on how many users shared the post, which was also calculated using user accounts as identification. For data accuracy, this study examined the user accounts linked to each "like," "comment," and "share" and discovered that some of the likes and shares were by the florists themselves. To avoid those entries resulting in bias, we excluded such posts from all subsequent analyses. Besides, posts with extraordinarily high numbers of likes, comments, and shares that fell beyond three standard deviations of the mean were considered outliers (Shiffler, 1988). We also excluded these posts from all subsequent analyses. As a result, 17 posts were excluded, leaving 1629 posts for the subsequent statistical analyses.

Afterward, this study adopted the ANOVA approach to test whether post content and media format had significant effects on the number of likes, comments, and shares from users. If so, a post hoc test was conducted to investigate the differences in the effect of triggering users to like, comment on, or share posts (Hair et al., 2010).

\section{Results and Discussion}

\section{The taxonomy of florists' Facebook posts}

The results of the content analysis suggested that florists' posts could be classified into 12 categories, being combined into four major types based on the intentions that florists attempted to convey with the posts. The definitions and examples of these post categories are presented in Table 1. Among these post categories, product information, work showcasing, gratitude to customers, and consumer education were the most common, accounting for $\approx 82.32 \%$ of the posts (Fig. 1). The characteristics of the posts by category are as follows.

Sales posts. These posts mainly attempted to convey the messages that are generally required for consumers' purchase decisions, such as the messages about the products, services, operating hours, or sales of the flower shop. This type of post can be further divided into the following four categories.

1. Product information: These posts included information about the operating items of the flower shop, such as the names, prices, and standards of the items. This category also covered the descriptions of noteworthy products or services. For example, posts carrying messages about the type of flowers, the contents of floral design courses, and venue decoration services were classified into this category.

2. Sales promotion: These posts concerned promotions such as giveaways, lotteries, limited time offers, and price reductions. Studies have defined promotional messages as a type of reward feedback that provides consumers with financial rewards and feedback (Coursaris et al., 2013).

3. Business information: These posts had to do with flower shops' operating policies, cooperation relationships, changes in business hours, and product purchase procedures. Previous studies have indicated that companies in certain industries may make operation announcements, including openings, operational status, financial status, cooperation relationships, or emergencies, on their Facebook brand pages (Coursaris et al., 2013; Hannah and Lam, 2017).

4. Consumer education: These posts were concerned with sharing knowledge on planting, caring for or using flowers, and included the language of flowers, suitable occasions for giving flowers as gifts, or simple do-it-yourself skills in flower arrangement, etc. Previous studies have indicated that educational posts in other industries mostly focus on product knowledge (Coursaris et al., 2013; Hannah and Lam, 2017). By contrast, florists' posts cover a wider range of product knowledge to provide consumers with more comprehensive gardening knowledge.

Brand image posts. These posts are mainly to do with floral designs, brand events, or the social activities in which the florists participate. The purpose is to improve the image of the flower shop. Posts of this type can be divided into the following four categories:

1. Work showcasing: These posts generally featured photos, and their contents mainly concerned florists' floral designs or venue display services. Compared with product information posts, work showcasing posts are mainly for displaying and sharing the florists' work, as well as recording and demonstrating florists' creations. Florists post them to demonstrate their professionalism in floral design and not to sell these products. Thus, the posts do not normally feature commercial information. Sometimes, florists seek users' opinions on these posts to increase interactions with users.

2. Image construction: In this category, the posts mainly constructed a positive image of the flower shop, which is a strategy for increasing a company's image (Kwok and Yu, 2016). Florists in this study had posting strategies of promoting their insistence on quality and emphasis on clients to boost their brand image.

3. Brand events: These posts concerned public relations activities hosted by flower shops, lectures related to the flower shop's brand, or event information. Furthermore, their contents encompassed celebrity endorsements, sponsorship of competitions, and brand promotion activities. The main goal is to deliver consumers brand information and achievements (Coursaris et al., 2013; Kwok and Yu, 2016; Su et al., 2015).

4. Charity events: The main goal of these posts was to provide exposure of when florists participate in or host charity events, and call for consumers' participation. This is a demonstration of the florists' social responsibility and can be considered to be a type of altruistic news (Hannah and Lam, 2017).

Interaction posts. These posts were generated as a florist actively sends messages to establish interaction with users for a favorable customer relationship. Posts of this type can be divided into three categories.

1. Gratitude to customers: These posts were concerned with florists' gratitude to customers who had ordered their products. Usually, these posts feature the floral products purchased and the customers' stories regarding the purchases. Although these posts can have the function of demonstrating the florists' professional ability in floral design, they differ from work showcasing posts because they specifically help in advertising the customers' business or send words of blessing to customers. For example, "Thank you for ordering our products. We wish Sanxia X (the shop's name) Noodle Shop a booming business." Posts in this category frequently appear on florists' Facebook pages. By contrast, enterprises in several industries may post this type of post only when they reach a certain milestone in terms of the number of Facebook fans (Coursaris et al., 2013; He et al., 2013).

2. Holiday greetings: These posts concern the wishes and care that florists demonstrate for their customers on holidays or when major disasters strike. In general, their content does not involve promotions or advertisements but only delivers messages to greet customers or express sympathy. For example, "The typhoon has passed and the sky has cleared. Time to restock. Have you started to clean up your home?" Studies have indicated that enterprises in other industries also frequently post this type of content on Facebook (Coursaris et al., 2013; Kwok and Yu, 2016). 


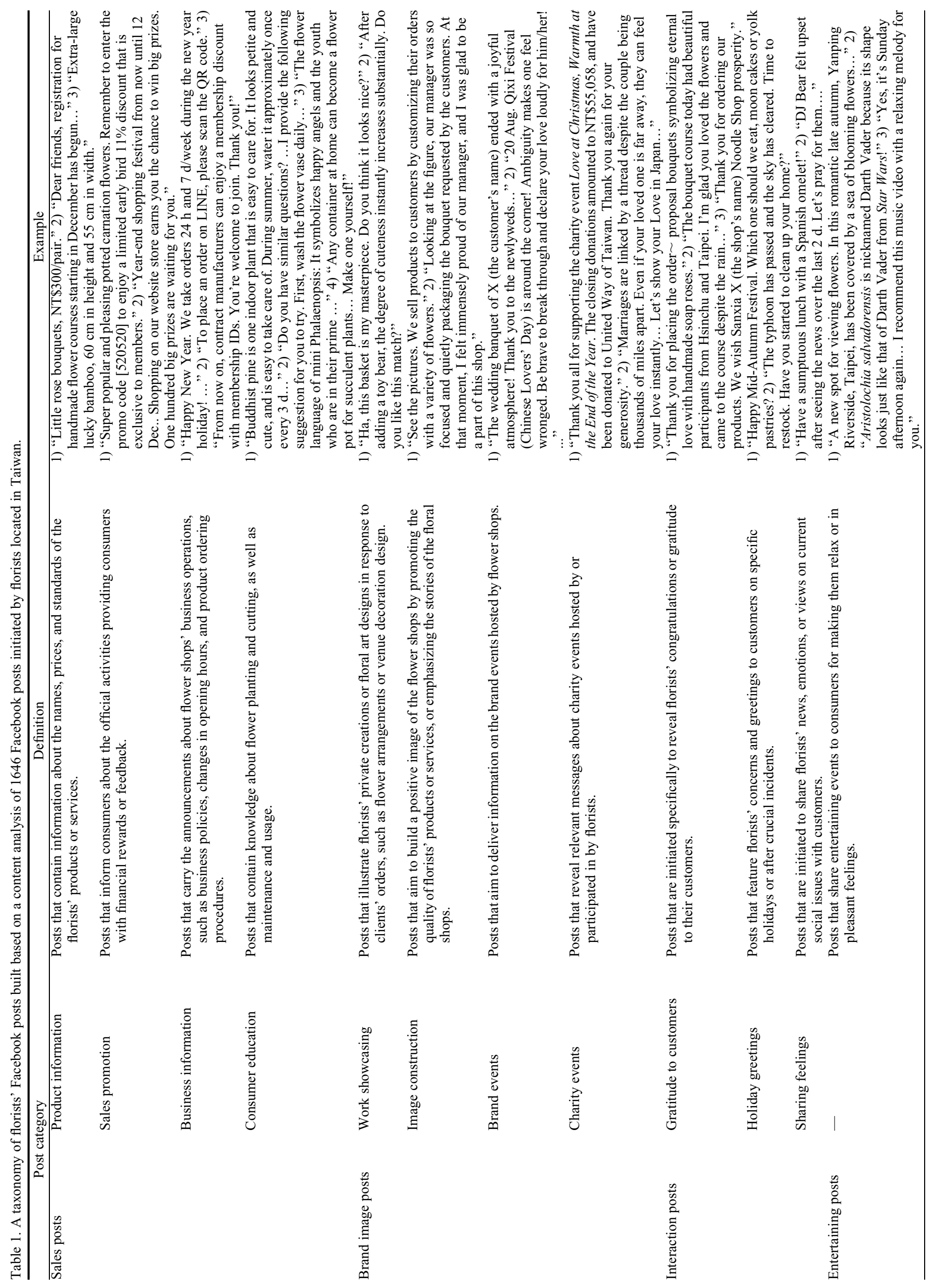




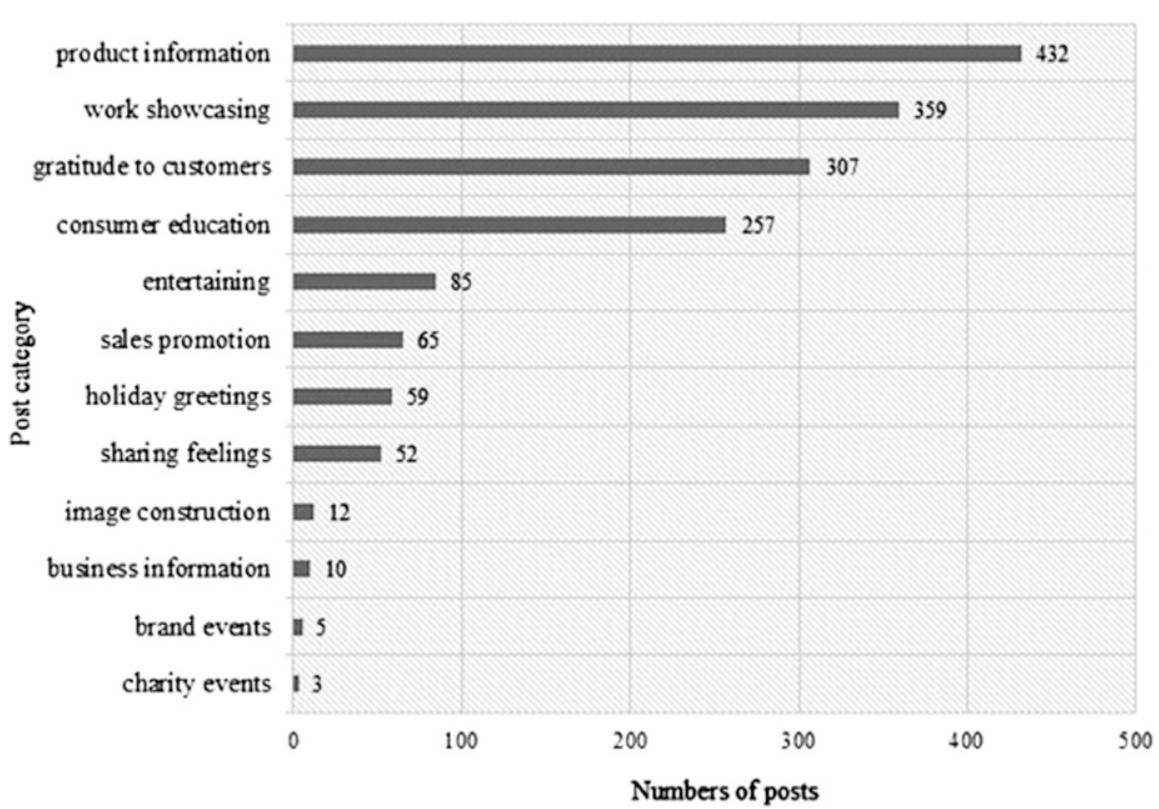

Fig. 1. The number of posts in each post category classified based on the content of 1646 Facebook posts initiated by the florists located in Taiwan.

3. Sharing feelings: These posts concern florists sharing recent personal news, feelings, or social commentary with users. Many enterprises post this type of post to encourage inspired users to interact, and some researchers have termed this type of post a "social post" (Luarn et al., 2015). This study discovered that florists not only share personal views or feelings on specific incidents but also constantly update their personal news; florists share their daily lives with users, as if they were part of the brand. To manage this type of post, florists often give themselves nicknames, such as "Curator" or "DJ Bear," to shorten their distance from users.

Entertaining posts. This category refers to posts or reposts that share entertainmentrelated events. No subcategory was defined for this type of post because of their similarity in content. Entertaining posts were mostly flower related, such as rare flower types or floral viewing activities. Studies have indicated that the content of these posts by enterprises in several industries is often related to novel art creations, jokes, or things that make customers relax or induce pleasant feelings in them (Cvijikj and Michahelles, 2013; De Vries et al., 2012; Hannah and Lam, 2017; Luarn et al., 2015; Tafesse, 2015). However, such content did not often appear in the entertaining posts of florists.

\section{The effect of post content and media format in terms of triggering users' engagement behaviors}

In relation to this, using ANOVA, we analyzed the effect of post content on users' response behaviors of liking, commenting on, and sharing posts. The average numbers of likes, comments, and shares gained from users for each post content category are presented in Table 2. Because the sample size of the post categories of image construction, business information, brand events, and charity events was less than 20 , posts in these categories were excluded from the operation of ANOVA to ensure the robustness of the statistical results (DasGupta and Vidakovic, 1997). Before using ANOVA, the observations across the post categories were found to exhibit variance heterogeneity using the Brown-Forsythe test (Brown and Forsythe, 1974a), as presented in Table 3. For this reason, the potential statistical bias caused by variance heterogeneity needed to be considered (Box, 1954). Therefore, the statistical results from using ANOVA were explained with Welch's F test (Brown and Forsythe, 1974b; Welch, 1951). As a result, the statistical results verified that post content had a significant effect on users' liking, commenting on, and sharing florists' Facebook posts (Table 3). This study further adopted the Games-Howell post hoc test to complete the multiple comparisons (Games and Howell, 1976).

The statistical results of the post hoc test indicated that posts in the categories of product information, gratitude to customers, or holiday greetings received likes from users more easily than did other categories of posts. Furthermore, posts in the categories of product information and gratitude to customers received more comments than did other categories of posts, and the posts in the category of product information were also shared more times by users than were other posts (Table 3 ).

These above results indicate that based on florists' current message strategies for their Facebook posts, product information, gratitude to customers, and holiday greetings are the most attractive types of posts to Facebook users and can induce greater responses. However, their effects in terms of stimulating users' response behaviors vary. For example, holiday greetings encourage users to like the posts, but not to comment on or share them. Furthermore, gratitude to customers prompts users to like and comment on posts, whereas product information posts encourage all three response behaviors. By contrast, post content related to work showcasing, consumer education, sharing feelings, and entertaining received fewer responses. Even though the post categories of sales promotion and sharing feelings had high averages in the observations of likes, comments, and shares gained from users, they had not statistically proved to be better than other post categories in terms of stimulating users' response behaviors (Tables 2 and 3 ).

These findings were consistent with those of previous studies in the following aspects: 1) similar to the studies conducted on the hotel, food/beverage, and automobile industries, the post content had a significant effect on users' response behaviors toward florists' Facebook posts (Cvijikj and Michahelles, 2013; Kim et al., 2015; Kwok and Yu, 2016; Leung et al., 2017; Tafesse, 2015) and 2) compared with other categories of posts, product information posts had more favorable integrated effects in terms of triggering users to like, comment on, and share florists' posts, and this phenomenon has been observed in previous studies on various industries (Cvijikj and Michahelles, 2013; Leung et al., 2017; Luarn et al., 2015). However, some aspects of the findings were different from those of previous studies: 1) Posts expressing care for customers seemed to be more attractive to consumers in the floral industry than in other industries (Kim et al., 2015; Su et al., 2015). The reason may be that flowers differ from general consumables in that their product value lies in their symbolic meanings and emotional values. Therefore, the Facebook users that florists attract might be more romantic and thus might be more willing to respond to the posts that are more emotionally connected, such as the posts showing care for consumers. 2) Entertaining posts seem to be less attractive to users because they are less likely to inspire users' engagement behaviors compared with other types of posts, which differs greatly from the Facebook management situations observed in other industries (Cvijikj and Michahelles, 2013; Luarn et al., 2015; Tafesse, 2015). Generally speaking, entertaining posts on Facebook include content such as jokes, novelties, or daily entertainment activities. They can induce laughter or relaxed feelings in consumers and easily trigger favorable responses. Therefore, the finding that entertaining posts do not attract the attention of users in terms of favorable responses in this study may be attributable to the fact that the entertaining posts on florists' Facebook pages were mostly about messages to do with floral sight-seeing activities, which were mostly reposted from other sources. The content of these posts differs greatly from that of the entertaining posts in other industries. It 
Table 2. Means of likes, comments, and shares received from users for each of the post content categories based on the data for 1629 empirical Facebook posts initiated by florists located in Taiwan.

\begin{tabular}{|c|c|c|c|c|c|}
\hline \multirow[b]{2}{*}{ Post category } & \multirow[b]{2}{*}{ Sample size } & \multirow[b]{2}{*}{ Percentage (\%) } & \multicolumn{3}{|c|}{ Mean } \\
\hline & & & Like & Comment & Share \\
\hline Work showcasing & 359 & 22.04 & 4.65 & 0.08 & 0.06 \\
\hline Entertaining & 85 & 5.22 & 4.29 & 0.13 & 0.06 \\
\hline Holiday greetings & 58 & 3.56 & 13.14 & 0.19 & 0.22 \\
\hline Sales promotion & 56 & 3.44 & 25.59 & 0.32 & 0.18 \\
\hline Business information & 9 & 0.55 & 13.89 & 0.44 & 0.44 \\
\hline Brand event & 5 & 0.31 & 20.40 & 7.00 & 0.20 \\
\hline Charity event & 2 & 0.12 & 6.50 & 0.00 & 0.50 \\
\hline
\end{tabular}

Table 3. Statistical results of analysis of variance (ANOVA) and the post hoc test for analyzing the effect of post content in terms of triggering users' response behaviors in the form of likes, comments, and sharing florists' Facebook posts based on the data for 1629 empirical posts initiated by florists located in Taiwan.

\begin{tabular}{|c|c|c|c|c|c|c|c|}
\hline \multirow{2}{*}{$\begin{array}{l}\text { Response } \\
\text { behavior }\end{array}$} & \multicolumn{3}{|c|}{$\begin{array}{l}\text { Variance heterogeneity } \\
\text { (Brown-Forsythe test) }\end{array}$} & \multicolumn{3}{|c|}{ ANOVA } & \multirow[b]{2}{*}{ Post hoc test } \\
\hline & $\mathrm{df}_{1}$ & $\mathrm{df}_{2}$ & $\mathrm{~F}$ & $\overline{\mathrm{df}_{1}}$ & $\mathrm{df}_{2}$ & $\mathrm{~F}$ & \\
\hline Like & 7 & 97.89 & $3.93 * *$ & 7 & 294.22 & $14.00 * * *$ & $\begin{array}{l}\text { Product information }>\text { Work showcasing*** } \\
\text { Product information }>\text { Consumer education*** } \\
\text { Product information }>\text { Entertaining*** } \\
\text { Gratitude to customers }>\text { Work showcasing*** } \\
\text { Gratitude to customers }>\text { Consumer education } * * * \\
\text { Gratitude to customers }>\text { Entertaining*** } \\
\text { Holiday greetings }>\text { Work showcasing** } \\
\text { Holiday greetings }>\text { Consumer education* } \\
\text { Holiday greetings }>\text { Entertaining** }\end{array}$ \\
\hline Comment & 7 & 482.20 & $3.99 * * *$ & 7 & 292.05 & $6.10 * * *$ & $\begin{array}{l}\text { Product information }>\text { Consumer education* } \\
\text { Gratitude to customers }>\text { Work showcasing** } \\
\text { Gratitude to customers }>\text { Consumer education*** }\end{array}$ \\
\hline Share & 7 & 580.91 & $5.03 * * *$ & 7 & 293.69 & $4.19 * * *$ & Product information $>$ Gratitude to customers* \\
\hline
\end{tabular}

$* P \leq 0.05 ; * * P \leq 0.01 ; * * P \leq 0.001$.

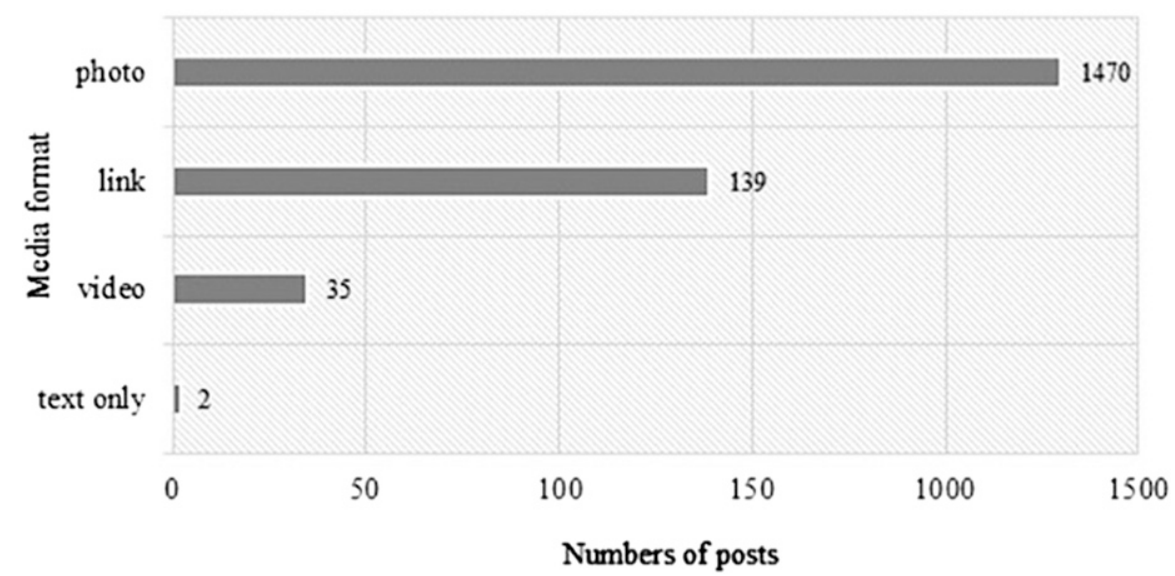

Fig. 2. The number of posts in each post category classified based on the media format of 1646 Facebook posts initiated by the florists located in Taiwan.

lacks social commentary, news, jokes, or novelties. This may cause entertaining posts on florists' Facebook pages to fail to induce favorable consumer responses.

In this area, we also investigated the effect of media format in terms of triggering users' response behaviors toward florists' Facebook posts. Across all types of media formats adopted in florists' posts, the photo was the most common format, accounting for $89.31 \%$ of all posts (Fig. 2). This dominant proportion may relate to the fact that florists use their Facebook brand pages to announce product information or share their work in abundance (Fig. 1), so they need to heavily rely on visual presentations as they compose their Facebook posts. The average numbers of likes, comments, and shares received by the posts categorized according to the type of media format are presented in Table 4.

With the same statistical procedures of ANOVA and the post hoc test used previously in this study for analyzing the effect of post content, the study's results also revealed that the numbers of likes, comments, and shares gained from Facebook users exhibited significant differences across the posts with the different media formats of photos, videos, and links (Table 5). Evidently, media format exerted a significant effect on users' response behaviors. Compared with the posts with videos or links, posts with photos were more effective in terms of attracting users' likes, comments, and shares, a finding that concurs with those from previous studies in the hotel and food/ beverage industries (Cvijikj and Michahelles, 2013; Kwok and Yu, 2013; Leung et al., 2017). However, some scholars have obtained different results. For example, Luarn et al. (2015) studied Facebook posts from multiple industries and discovered that posts with videos received more likes, comments, and shares than posts employing other types of media. In addition, Kim et al. (2015) studied the Facebook posts of companies in multiple industries, and discovered that, whereas media format had a significant effect on users' response behaviors, the most effective media differed between industries.

\section{Conclusions}

This study has used empirical data to develop a taxonomy of florists' Facebook posts and to analyze the effect of the content and media format of florists' posts on users' engagement behaviors. The study's results reveal that florists' Facebook posts can be classified into four types with 12 categories in terms of post content, and the four categories 
Table 4. Means of likes, comments, and shares received from users for posts in different media formats analyzed based on the data for 1629 empirical Facebook posts initiated by florists located in Taiwan.

\begin{tabular}{lccrr}
\hline & & & & \multicolumn{2}{c}{ Mean } \\
\cline { 3 - 5 } Media format & Sample size & Percentage (\%) & Like & Comment \\
\hline Photo & 1,453 & 89.20 & 10.24 & 0.20 \\
Link & 139 & 8.53 & 1.37 & 0.03 \\
Video & 35 & 2.15 & 5.00 & 0.11 \\
Text only & 2 & 0.12 & 38.50 & 0.01 \\
\hline
\end{tabular}

Table 5. Statistical results of analysis of variance (ANOVA) and the post hoc test for analyzing the effect of posts' media formats on users' response behaviors in terms of likes, comments, and sharing florists' Facebook posts based on the data for 1629 empirical posts initiated by florists located in Taiwan.

\begin{tabular}{|c|c|c|c|c|c|c|c|}
\hline \multirow[b]{2}{*}{ Response behavior } & \multicolumn{3}{|c|}{ Variance heterogeneity (Brown-Forsythe test) } & \multicolumn{3}{|c|}{ ANOVA } & \multirow[b]{2}{*}{ Post hoc test } \\
\hline & $\mathrm{df}_{1}$ & $\mathrm{df}_{2}$ & $\mathrm{~F}$ & $\overline{\mathrm{df}_{1}}$ & $\mathrm{df}_{2}$ & $\mathrm{~F}$ & \\
\hline
\end{tabular}

$* P \leq 0.05 ; * * P \leq 0.01 ; * * * P \leq 0.001$.

of product information, work showcasing, customer gratitude, and consumer education account for the greatest proportion of total posts. In general, the content of florists' Facebook posts is similar to that of other industries' posts, that is, it is diverse and mostly consists of the information about products, brands, or customer relationships. However, this study discovered that compared with other industries, florists are less likely to post interaction posts to trigger users' feedback. Nonetheless, florists share their floral design works more often to demonstrate their professionalism to users and more frequently post socializing posts to thank consumers for buying their products, express care to consumers, or share their thoughts and feelings to establish favorable relationships.

The hypotheses of this study were validated to observe that the content and media format of florists' Facebook posts had significant effects in terms of triggering users to like, comment on, and share the posts. In general, posts with content on product information, gratitude to customers, and holiday greetings were most effective in eliciting users' responses. In particular, posts with product information had the most favorable integrated effects in terms of triggering users to like, comment on, and share the posts. As regards the effect of media format, the posts containing photos were more likely to cause users to like, comment on, or share florists' posts in comparison with the posts presented in other media formats. These findings support the suggestion by Hall et al. (2012) that content management and the use of multimedia in posting are critical to the success of florists' social media marketing. However, the findings of the current study are partially different from the previous study conducted by Yue et al. (2016) regarding consumers' preference for the content of florists' posts. In that study, which aimed to assess millennial consumers' floral purchasing behaviors, Yue et al. (2016) found that millennials preferred to share florists' posts which contained free giveaways, coupons/discounts, floral art, or funny and humorous flower-related videos, in contrast to the findings of the current study that posts characterized by sales promotion, entertaining, and work showcasing revealed a neutral attitude or were less effective in terms of triggering Facebook users to like, comment on, or share florists' posts. The contrast may be attributable to the difference between the generations and cultures in the samples, that is, one sample consisted of millennials who were born in a Western culture, and the other of multiple generations living in an Eastern culture.

This study also discovered that the effect of work showcasing, consumer education, and entertaining posts in terms of triggering consumers to like, comment on, or share posts was weaker than expected. This would suggest that these three categories of posts need to be improved.

1. Work showcasing posts: Work showcasing posts share florists' art creations in floral design, but this study discovered that these posts do not ignite heated discussion from users that would have been expected. To determine possible reasons for this, this study investigated the content of this type of post, and discovered that florists rarely provide indepth verbal interpretations of their works in the photos. This study therefore suggests that florists could deepen their textual descriptions to include more information and imagination in such posts. For example, they could add a design process, thoughts, and reflections to the text in relation to these posts. It helps in boosting the imagination of users in relation to the floral design work in the photos and increases the attractiveness of these posts to users.

2. Consumer education posts: This type of post provides knowledge about flowers or gardening, which is expected to be attractive to consumers because it fulfills consumers' needs for information as they purchase flowers either for personal use or as gifts. However, this study revealed that Facebook users are not particularly enthusiastic about responding to posts in this category. This study suggests that florists should clarify the information preferences of their online customers in planning the content of their consumer education posts.

3. Entertaining posts: Several studies have revealed that entertaining posts exhibit favorable Facebook marketing effects (Cvijikj and Michahelles, 2013; Luarn et al., 2015; Tafesse, 2015). However, the entertaining posts in this study did not indicate ideal effects in terms of triggering responses from users. This study observed that, compared with their counterparts in other industries, florists post relatively few entertaining posts and the content of these posts is often limited to activities related to flowers or gardening, unlike the entertaining posts of other industries that have a more extensive content in terms of jokes, current social issues, and hot topics in daily life, etc. Thus, the content of the entertaining posts observed in this study might have seemed monotonous to users, which possibly resulted in their not being well-received. We therefore suggest that when composing entertaining Facebook posts, florists should increase the diversity of the content to increase the posts' marketing effectiveness.

This study provides an insight into the message strategies of florists on Facebook brand pages, as well as the effect of posted content and media format on users' engagement behaviors. It enriches our understanding of the multiplicity of ways in which florists can increase their appeal to consumers on Facebook. Users' various engagement behaviors imply a variety of meanings for Facebook brand page management. Liking a post reveals the trust, agreement, and preference of a user for the post (Tafesse, 2015). By contrast, sharing a post is considered to be an indicator that reflects a consumer's acknowledgment of the post and 
a willingness to advertise it through word of mouth, the deepest level of the brand involvement of a consumer (Hoffman and Fodor, 2010; Kwok and Yu, 2013; Tafesse, 2015). Once users share a post, they expose it to members outside the enterprise's Facebook social group, increasing the exposure of the enterprise's brand. This study has suggested that florists should post content based on consumers' preferences for the content and media formats of posts to increase consumers' interest in the posts, thereby deepening the response of consumers and enlarging the marketing efficiency of florists' Facebook brand pages.

We recommend that future research aim at investigating the existence of additional factors that might influence the level of consumers' engagement behaviors in relation to florists' Facebook posts, such as the posting frequency, community size of fans, and promotion strategies of florists, to increase the effectiveness of florists' social media marketing through the operation of Facebook brand pages.

\section{Literature Cited}

Anderson, M., J. Sims, J. Price, and J. Brusa. 2011. Turning "like" to "buy" social media emerges as a commerce channel. Booz \& Company Inc. 2(1):102-128.

Baird, C.H. and G. Parasnis. 2011. From social media to social customer relationship management. Strategy Leadersh. 39(5):30-37.

Box, G.E.P. 1954. Some theorems on quadratic forms applied in the study of analysis of variance problems, I. Effect of inequality of variance in the one-way classification. Ann. Math. Stat. 25(2):290-302.

Brown, M.B. and A.B. Forsythe. 1974a. Robust tests for the equality of variances. J. Amer. Stat. Assn. 69(346):364-367.

Brown, M.B. and A.B. Forsythe. 1974b. The small sample behavior of some statistics which test the equality of several means. Technometrics 16(1):129-132.

Corbin, J. and A. Strauss. 1990. Grounded theory research: Procedures, canons and evaluative criteria. Z. Soziol. 19(6):418-427.

Coursaris, C.K., W. Van Osch, and B.A. Balogh. 2013. A social media marketing typology: Classifying brand Facebook page messages for strategic consumer engagement. ECIS 2013 Proc.: 46.

Crabtree, B.F. and W.L. Miller. 1992. A template approach to text analysis: Developing and using codebooks, p. 93-109. In: B.F. Crabtree and W.L. Miller (eds.). Doing qualitative research. Sage, Newbury Park, CA.

Cvijikj, I.P. and F. Michahelles. 2013. Online engagement factors on Facebook brand pages. Soc. Netw. Anal. Min. 3(4):843-861.
Daft, R.L. and R.H. Lengel. 1986. Organizational information requirements, media richness and structural design. Mgt. Sci. 32(5):554-571.

DasGupta, A. and B. Vidakovic. 1997. Sample size problems in ANOVA Bayesian point of view. J. Stat. Plan. Inference 65(2):335-347.

De Vries, L., S. Gensler, and P.S.H. Leeflang. 2012. Popularity of brand posts on brand fan pages: An investigation of the effects of social media marketing. J. Interactive Mktg. 26(2):83-91.

Downe-Wamboldt, B. 1992. Content analysis: Method, applications, and issues. Health Care Women Intl. 13(3):313-321.

Games, P.A. and J.F. Howell. 1976. Pairwise multiple comparison procedures with unequal n's and/or variances: A Monte Carlo study. J. Educ. Behav. Stat. 1(2):113-125.

Gerlitz, C. and A. Helmond. 2013. The like economy: Social buttons and the dataintensive web. New Media Soc. 15(8):13481365.

Hair, J.F., Jr., W.C. Black, B.J. Babin, and R.E. Anderson. 2010. Multivariate data analysis: A global perspective. 7th ed. Pearson, Upper Saddle River, NJ.

Hall, C., J. Korhan, B. Behe, and C. Yue. 2012. A social media guide for floral retailers and wholesalers. Floral Mktg. Res. Fund, Alexandria, VA.

Hannah, M.A. and C. Lam. 2017. Drawing from available means: Assessing the rhetorical dimensions of Facebook practice. Intl. J. Bus. Commun. 54(3):235-257.

He, W., S. Zha, and L. Li. 2013. Social media competitive analysis and text mining: A case study in the pizza industry. Intl. J. Inf. Mgt. 33(3):464-472.

Hoffman, D.L. and M. Fodor. 2010. Can you measure the ROI of your social media marketing? MIT Sloan Mgt. Rev. 52(1):41-49.

Irani, T.A., D. Clark, B. Raulerson, and D. Slough. 2011. Not your grandmother's flowers: What combination of flower fragrance and color is preferred by young adult consumers? Amer. Floral Endowment, Alexandria, VA.

Kaplan, A.M. and M. Haenlein. 2010. Users of the world, unite! The challenges and opportunities of social media. Bus. Horiz. 53(1):59 68.

Kassarjian, H.H. 1977. Content analysis in consumer research. J. Consum. Res. 4(1):8-18.

Kim, D.H., L. Spiller, and M. Hettche. 2015. Analyzing media types and content orientations in Facebook for global brands. J. Res. Interactive Mktg. 9(1):4-30.

Kwok, L. and B. Yu. 2013. Spreading social media messages on Facebook: An analysis of restaurant business-to-consumer communications. Cornell Hosp. Q. 54(1):84-94.

Kwok, L. and B. Yu. 2016. Taxonomy of Facebook messages in business-to-consumer communications: What really works? Tour. Hosp. Res. 16(4):311-328.
Lengel, R.H. and R.L. Daft. 1988. The selection of communication media as an executive skill. Acad. Mgt. Exec. 11(3):225-232.

Leung, X.Y., B. Bai, and M. Erdem. 2017. Hotel social media marketing: A study on message strategy and its effectiveness. J. Hosp. Tour. Technol. 8(2):239-255.

Luarn, P., Y.F. Lin, and Y.P. Chiu. 2015. Influence of Facebook brand-page posts on online engagement. Online Inf. Rev. 39(4):505-519.

Microsoft. 2018. Getting started with power query. 7 Aug. 2018. <https://support.office.com/enus/article/getting-started-with-power-query7104 fbee-9e62-4cb9-a02e-5bfb1a6c536a? $\mathrm{ui}=\mathrm{en}-\mathrm{US} \& \mathrm{rs}=\mathrm{en}-\mathrm{US} \& \mathrm{ad}=\mathrm{US}>$.

Nelson, R. 2010. Tech bytes [television series]. ABC Network, New York, NY.

Prince, T.L. and T.A. Prince. 2014. Florists broadly adopt social media. Payoff somewhat nil. Now what? Prince \& Prince, Inc., Columbus, $\mathrm{OH}$.

Russell Research. 2016. 2016 Generations of flowers study. Russell Res., Inc., East Rutherford, NJ.

Sabate, F., J. Berbegal-Mirabent, A. Cañabate, and P.R. Lebherz. 2014. Factors influencing popularity of branded content in Facebook fan pages. Eur. Mgt. J. 32(6):1001-1011.

Shiffler, R.E. 1988. Maximum Z scores and outliers. Amer. Stat. 42(1):79-80.

Stankov, U., L. Lazic, and V. Dragicevic. 2010. The extent of use of basic Facebook usergenerated content by the national tourism organization in Europe. Eur. J. Tour. Res. 3(2):105113.

Su, N., D. Reynolds, and B. Sunday. 2015. How to make your Facebook posts attractive: A case study of a leading budget hotel brand fan page. Intl. J. Contemp. Hosp. Mgt. 27(8):1772-1790.

Tafesse, W. 2015. Content strategies and audience response on Facebook brand pages. Mktg. Intelligence Planning 33(6):927-943.

Taipei Times. 2014. Taiwan likes Facebook, has highest penetration. 25 June 2016. <http://www. taipeitimes.com/News/biz/archives/2014/02/28/ 2003584495>.

Webb, C. 2014. Power query for power BI and Excel. Apress, New York, NY.

Weinberg, B.D. and E. Pehlivan. 2011. Social spending: Managing the social media mix. Bus. Horiz. 54(3):275-282.

Welch, B.L. 1951. On the comparison of several mean values: An alternative approach. Biometrika 38(3/4):330-336.

Wilson, A., H. Murphy, and J.C. Fierro. 2012. Hospitality and travel: The nature and implications of user-generated content. Cornell Hosp. Q. 53(2):220-221.

Yuan, C.H. 2010. Applying the unified theory of acceptance and use of technology to study the effect of customer intention and its relevant factors on the online florists (in Chinese). Chinese Cult. Univ., Taipei, MBA Thesis.

Yue, C., S. Zhao, and A. Rihn. 2016. Marketing tactics to increase millennial floral purchases. Amer. Floral Endowment, Alexandria, VA. 